\title{
Building Information Modeling for existing sustainable buildings
}

\author{
Natalya Braila ${ }^{1, *}$, Nikolai Panchenko ${ }^{1}$, and Vadim Kankhva ${ }^{2}$ \\ ${ }^{1}$ Peter the Great Saint-Petersburg Polytechnic University, Polytechnicheskaya st, 29, Saint-Petersburg \\ 195251, Russia \\ ${ }^{2}$ Moscow State University of Civil Engineering, 26, Yaroslavskoye shosse, Moscow, 129337, Russia
}

\begin{abstract}
The article is devoted to evaluation of the possibility of usage BIM for existing buildings. While BIM processes are established for new buildings, the majority of existing buildings is not maintained, refurbished or deconstructed with BIM yet. However, it can play a significant role for better operation and maintenance and building facility management. Research in creating BIM for existing buildings has received growing attention in recent years. The objective of this paper is to explore potential opportunities and barriers in constructing BIM for existing buildings
\end{abstract}

\section{Introduction}

In recent decades, the construction industry has seen a growing interest in the use of Building Information Modeling (BIM) due to the many advantages and resource savings during design and construction [1]. The BIM of an object contains information important for the construction and design stages, but it can also be useful during the operation phase for maintenance and management. Due to the long-life cycle of buildings, it is significant to take into account the operation stage and the dismantling stage to improve the efficiency of resource use.

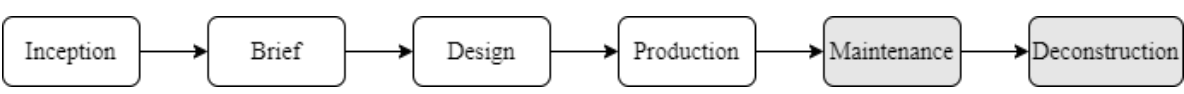

Fig. 1. Building LC stages following ISO 22263:2008

Currently, the use of BIM is more common at the stages of preliminary planning, design, construction and project implementation, however, recently, the use of BIM is spreading to later stages of the building life cycle, for example, maintenance, repair and dismantling [23].

The Building Information Model can be used as a convenient tool for analyzing energy consumption, detecting structural defects, providing fire extinguishing, repairs, and so on [4], but in many constructed buildings, the construction documentation is outdated or missing [35]. In Russia, most of the built residential buildings belong to the panel model series, the construction of which was carried out in the $50 \mathrm{~s}-70 \mathrm{~s}$, and as a result, for most of these

\footnotetext{
* Corresponding author: nashi-n-v@mail.ru
} 
buildings, the construction documentation is irrelevant and requires clarification, the Information Model was not created at the time.

Missing or outdated information can lead to inefficient project management and increased maintenance, operation, or upgrade costs. To implement the use of BIM for constructed buildings, it is needed to use up-to-date information or create an information model for each specific case.

Creating an Information Model is a complex and expensive process, which arises the need for special equipment for data collection, large modeling efforts, skilled personnel, as well as possible difficulties and obstacles in processing the obtained data, etc., but there are numerous potential BIM functionalities and benefits in existing buildings.

The purpose of the study is to determine the possibilities for using BIM for already constructed buildings.

To achieve this goal, the following tasks were completed:

1. An extensive analysis of the literature on the use of BIM for constructed buildings is carried out;

2. The specific needs, opportunities and potential obstacles in the implementation of BIM for constructed buildings are identified;

3. Conclusions about the possibility of using BIM for already constructed buildings are drawn.

\section{Possibilities of using the Building Information Model}

The Building Information Model (BIM) is defined by international standards as "shared digital representation of physical and functional characteristics of any built object which forms a reliable basis for decisions" [6]. The BIM is a shared knowledge resource for obtaining information about an object and serves as a basis for making decisions during the life cycle from concept to demolition. The BIM contains information about the object, its individual elements, geography, design, and other data, including the impact on the environment and vice versa, technical and economic indicators, and other characteristics of the object. [7-10].

Possible approaches to using BIM for existing buildings are diverse:

1. Operation and maintenance [3,11-15]

2. Life cycle assessment $[3,16,17]$

3. The calculation of the cost $[19,20-22]$

4. Space management [3]

5. Damage detection

6. Planning and performing repairs $[3,23,24]$

7. Energy and heat analysis and control [25]

8. Structural analysis [26-28]

9. Dismantling and organization of construction waste disposal [4]

10. Systematization and management of project documentation $[5,12,29,30]$ 


$$
\begin{aligned}
& \text { Availability of } \\
& \text { BIM model }
\end{aligned} \quad \text { BIM processes } \quad \text { Building LC stages }
$$

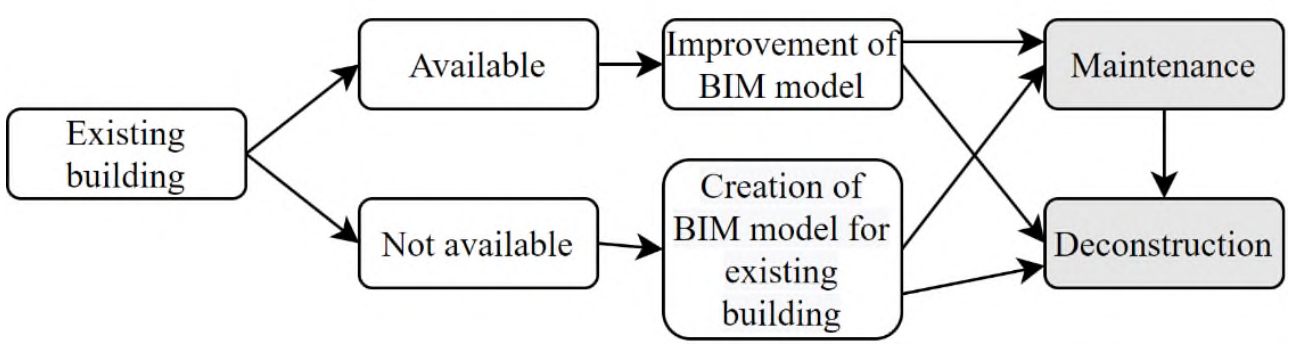

Fig. 2. BIM model creation processes in existing buildings depending on available BIM model [31].

For newly constructed buildings, the BIM is created during the design process. For existing buildings, depending on the availability of BIM and construction documentation, two options are possible (see pic. 2):

1. If there is a BIM and construction documentation, supplement and update the model is needed;

2. In the case of no BIM and construction documentation, a model (as built) from scratch should be created;

If there is a BIM for the object, the above functions can be performed with small adjustments, but if the BIM is not available or is not up-to-date, the creation process begins with a technical audit of the building, analysis of the construction documentation and determination of the current properties of the building (see pic.3).

\footnotetext{
Creation of

BIM model for

existing

building
}

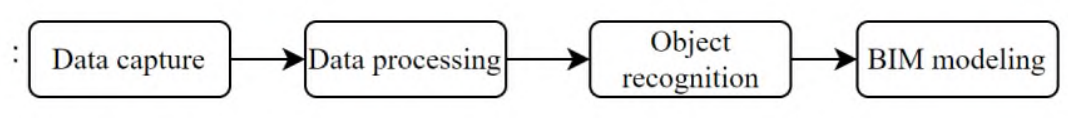

Fig. 3. BIM creation processes for new and existing buildings

This is necessary in order to provide a solid foundation for the use of the digital twin of the building in the future.

Since the number of existing residential buildings requiring maintenance exceeds the rate of new construction, the reconstruction and modernization of existing buildings is becoming increasingly important, but most existing buildings do not have a previously created BIM or sufficient construction documentation to create one, so we will discuss below the case of creating a BIM (as built) from scratch.

\section{Data capture}




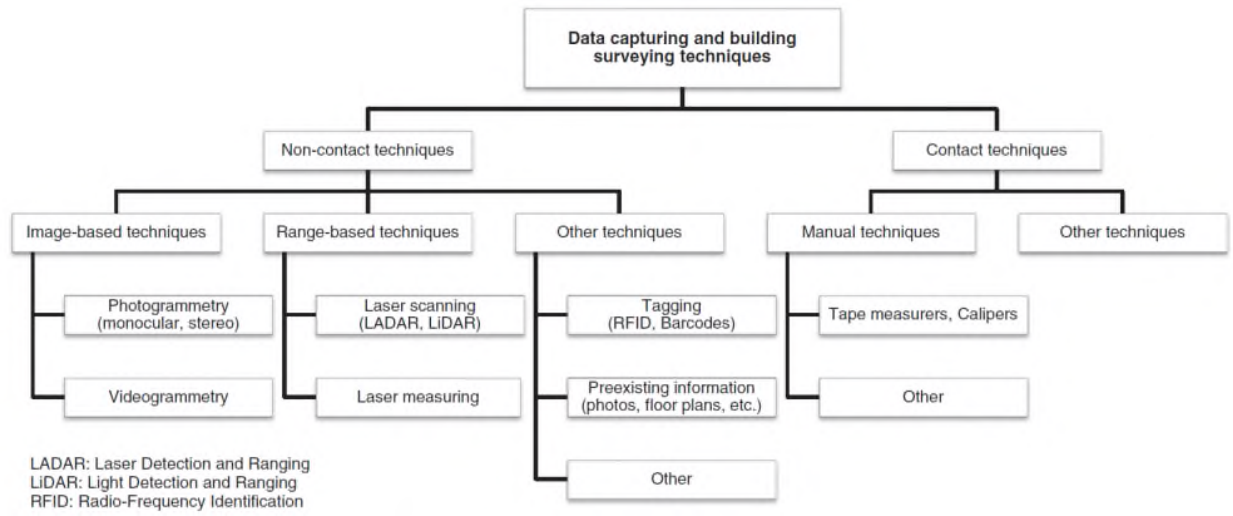

Fig. 4. Data capturing and building surveying techniques [32]

In this part of the work, we will talk about how to collect the information necessary to create a BIM (as built).

If, depending on the required functions, there is not enough information about the building, it is necessary to collect data. It should be noted that depending on the required functions, it is important to set the required Level of Detail (LoD), since the Level of Detail has a great impact on the quality of the data, the amount of data and the necessary effort to process the data. The Level of Detail determines all the next steps, from selecting a data collection technique to modeling.

Pic. 4 shows non-contact and contact data collection methods. Non-contact data collection methods are divided into image-based techniques, range-based techniques, and combined or other methods. Contact methods consist of manual or other methods [32-35]. Image-based and range-based techniques extract mainly information about space, color, and reflectivity.

Manual data collection methods allow to get mostly spatial information about the elements.

Other methods include methods such as tags [32, 36-37] or the use of pre-existing building information $[32,38]$ such as component sizes, materials, textures, functions, connections, positions, or maintenance periods.

As for RFID tags or tags with bar codes, these methods are rarely applicable to existing buildings, since these tags are installed mainly in new buildings [32, 39].

Combinations of methods are common, which allows us to overcome the shortcomings of individual methods [32, 35, 40-41].

The main characteristics when choosing a data collection method are cost, time, required LoD, and environmental conditions during data collection.

A common method used in practice is semi-automatic laser scanning using total stations $[32,42]$, this method has disadvantages, such as high cost and fragility of equipment, difficulties with scanning reflective, transparent and dark surfaces [32, 43-44], in addition, this method requires further extensive data processing and manual modeling, and the survey results are quite insignificant $(\mathrm{LoD})[8-9,13,32]$.

\section{Data processing}

Since future BIM functions determine the required level of detail (LoD) and the method of data collection, the functionality also affects the amount of data received, the processing, and the time and effort associated with this process. The processing of previously collected 
building data is performed to ensure that objects that are important for functionality are recognized, for example, to detect defects for maintenance purposes.

At the stage of data processing, point clouds obtained using image-based and range-based techniques are registered, aligned, and combined in a single coordinate system [9]. The data is then cleared of noise, unnecessary information, and clutter $[9,45]$ and often the number of points is reduced.

Data obtained using other methods is processed according to their data format, required functionality, and object recognition method [36, 38].

\section{Object recognition}

The collected and processed data about the building used to recognize the components of the buildings and their characteristics. Object recognition involves identifying an object, extracting information, and handling and removing clutter [9]. Object recognition methods and tools vary depending on: the geometric complexity, the LoD required, the data collection technique used, the data format, and the processing time.

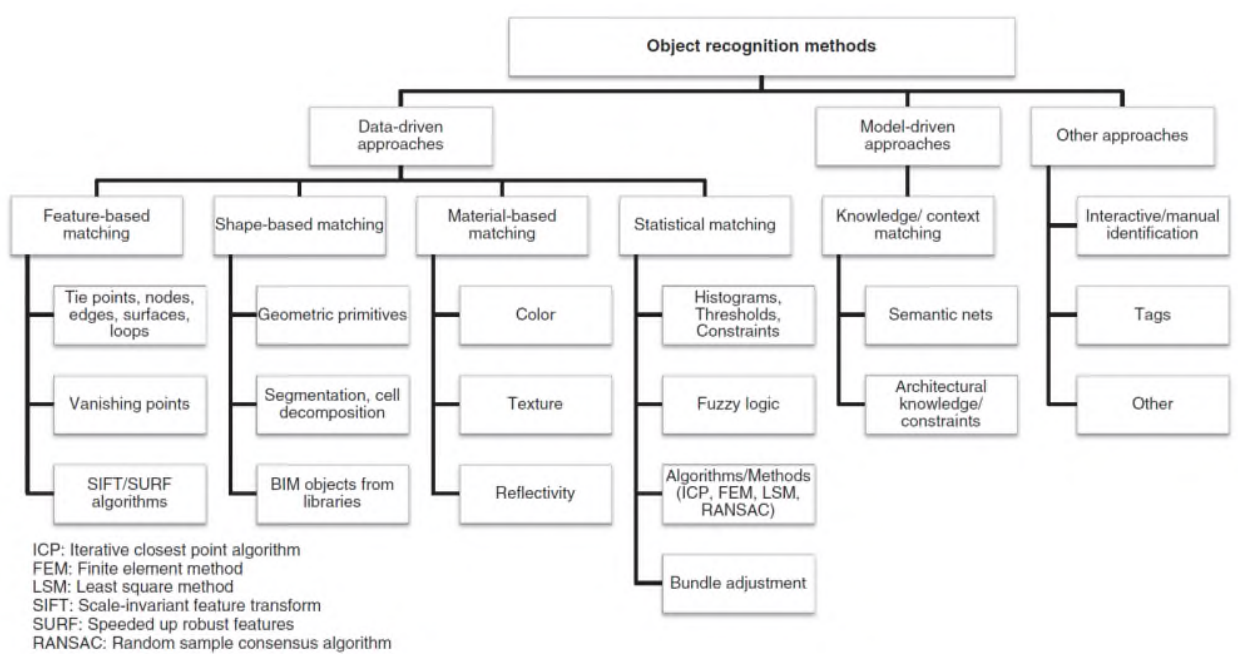

Fig. 5. Shows data-based, model-based, and other approaches to object recognition.

Data-driven approaches extract building information from collected and processed data and can be divided into methods based on characteristics, shape, materials, and statistical comparison.

Model-based approaches are based on the spatial and structural properties of geometric objects and the relationships that exist between them. Such approaches are based on collected data through knowledge or contextual information.

Other approaches include manual identification or tags.

There are also combined approaches, for example, based on data and models to eliminate the shortcomings of individual methods [32, 46-49].

Simple and flat building components, such as walls, ceilings, floors, doors, windows, and clutter, are recognized in small scenes of one or more rooms [32, 46-48] with recognition rates ranging from $89 \%$ to $93 \%$.

For BIM to be able to provide the function operation and maintenance, detailed information, for example, about the technical equipment, the length of the air duct, installation, layers of materials, connections and components, is drastically important. This 
information is not yet recognized automatically in buildings using modern approaches, and requires manual processing and a lot of work $[32,50]$.

\section{Modelling}

Modeling means creating BIM objects that represent building components and contain information about these components.

In practice, BIM modeling (as built) is performed manually, requires a lot of time, and the process is accompanied by possible errors [9, 34, 51]. Various software is used for modeling, for example, Autodesk Revit and Navisworks, Bentley Architecture, Graphisoft ArchiCAD, Tekla or Nemetschek Allplan. Although some of the listed programs allow to quickly create floor plans of a building, the presented software solutions are far from automated or semi-automated BIM modeling of existing buildings.

In modern research, automated BIM modeling is at the initial stage [51, 52]. Many publications cover semi-automated modeling of building surfaces or components with respect to their geometric representations. However, the presented approaches do not take into account the properties of the components and the information they possess. [53-62].

Hidden building components, such as electrical wiring, air ducts, or pipelines (HVAC / MEP), can only be modeled so far with a large number of human actions [50].

Due to the complex process of creating BIM, the creation of models of existing buildings is either focused on simple components, or is not applied.

A high LoD for maintenance is incompatible with the current time and financial constraints in the construction industry.

In addition, object attributes related to service functions are not yet well-defined, in part due to undefined properties, unavailable object libraries, or an undefined LoD.

Since BIM modeling of existing buildings requires skilled personnel and a lot of effort, further research in the field of automated data collection, processing and modeling can reduce the cost of building audits and increase the productivity of BIM-based maintenance processes.

\section{Future needs and Technical issues}

Although the use of BIM in existing buildings can contribute to better operation of the facility, the BIM implementation process faces serious shortcomings. The use of BIM in existing buildings is only possible if accurate and up-to-date information is available, and the quality of BIM data is critical for any application functionality. Thus, the main areas are, on the one hand, the collection of source data and the automatic creation of the BIM [40, 46, 52$53]$, and on the other hand, the processing and evaluation of information in the BIM $[3,63]$. The third important problem is the processing and modeling of indeterminate data.

The integration of data processing and collection methods in the BIM can provide automatic information updates, which will reduce time, costs and help to simplify the implementation of the BIM in existing buildings.

Due to the time-consuming process of collecting, processing and creating data, BIM modeling requires a lot of effort, and therefore is often not used in existing buildings.

In addition, the high level of detail (LoD) required for detailed consideration of maintenance issues is incompatible with the current time or financial constraints in the construction industry.

As a result, the main task is to reduce the effort of collecting, processing, recognizing and modeling information $[9,43,46,64]$; 
Therefore, the main trends in this area are aimed at developing an economical and automated creation of BIM based on laser scanning or photogrammetry.

But future trends may also include material or texture recognition [52], non-destructive testing techniques such as GPR, radiography, magnetic particle monitoring, sonar or electromagnetic waves [56], or tags installed during upgrades to increase the information saturation of the BIM. Further automation of the simulation of BIM objects from the collected data $[43,65]$ can be achieved through specific, but not yet available libraries of objects of real building components.

The recognition and modeling of hidden elements, such as equipment, air ducts and pipes, can be studied in accordance with the methods used in other areas of the construction industry [66].

\section{Conclusion}

The conducted literature review presented implementation and research of building information models (BIM) in existing buildings. Despite the increasing BIM usage in new structures, implementation of BIM in existing buildings is still limited yet, focusing on recently completed buildings with a BIM rather than on existing buildings without BIM.

Implementation of BIM for existing buildings has a great potential for operation and maintenance. However, the benefit of BIM has not been fully realized yet. This is because most of the existing buildings do not have a BIM and creating a BIM for existing building is challenging. BIM can be beneficial by many means, such as, lifecycle analysis for better facility management, sustainable and efficient energy use, cost effective retrofit decisionmaking, repair works, and organized demolition, but realizing these benefits faces major challenges.

As can be seen, major challenges are:

1. The automation of data capture and BIM creation (without preexisting BIM);

2. The update and maintenance of information in BIM;

3. The handling and modelling of uncertain data, objects and relations occurring in existing buildings in BIM;

4. Varying quality assessments of BIM models

5. Interoperability between BIM models of different generations

6. Underdeveloped object properties and processes for maintenance purposes

New data capturing techniques try to overcome lacking building information at low costs. However, current approaches face challenges of capturing structural, concealed or semantic building information under changing environmental conditions and of transforming captured data into unambiguous semantic BIM objects and relationships.

Adaptation of BIM-related legal and organizational frameworks differs between countries. Progressive countries reformed national regulations and implemented novel collaboration processes through BIM, but rather for new than for existing buildings.

Fast developments of BIM and the recent release of standards such as COBie are promising for future process automation and efficient resource management through BIM in existing buildings.

Hence, there is a great potential of research opportunities in creating economic and automatic BIM for existing building. 


\section{References}

1. EU Parliament and the Council, Regulation (EU) No 305/2011 of the European Parliament and of the Council of 9 March 2011 Laying Down Harmonised Conditions for the Marketing of Construction Products and Repealing Council Directive 89/106/EEC (2011)

2. D. Bryde, M. Broquetas, J.M. Volm, The project benefits of Building Information Modeling (BIM), Int. J. Proj. Manag., 31, 971-980 (2013)

3. B. Becerik-Gerber, F. Jazizadeh, N. Li, G. Calis, Application areas and data requirements for BIM-enabled facilities management, J. Constr. Eng. Manag., 138, 431442 (2012)

4. J. Cheng, L. Ma, A BIM-based system for demolition and renovation waste quantification and planning, Proceedings of the 14th International Conference on computing in Civil and Building Engineering (ICCCBE 2012) (Moskow, 2012)

5. I. Gursel, S. Sariyildiz, Ö. Akin, R. Stouffs, Modeling and visualization of lifecycle building performance assessment, Adv. Eng. Inform., 23, 369-417 (2009)

6. ISO Standard, ISO 29481-1:2010(E): Building Information Modeling - Information Delivery Manual — Part 1: Methodology and Format (2010)

7. T. Cerovsek, A review and outlook for a "Building Information Model (BIM)": a multistandpoint framework for technological development, Adv. Eng. Inform., 25, 224-244 (2011)

8. A. Watson, Digital buildings - challenges and opportunities, Adv. Eng. Inform., 25, 573-581 (2011)

9. P. Tang, D. Huber, B. Akinci, R. Lipman, A. Lytle, Automatic reconstruction of as-built building information models from laser-scanned point clouds: a review of related techniques, Autom. Constr., 19, 829-843 (2010)

10. G. Lee, R. Sacks, C. Eastman, Specifying parametric building object behavior (BOB) for a building information modeling system, Autom. Constr., 15, 758-776 (2006)

11. J. Lucas, T. Bulbul, W. Thabet, An object-oriented model to support healthcare facility information management, Autom. Constr., 31, 281-291 (2013)

12. A. Akcamete, B. Akinci, J. H. Garrett Jr., Potential utilization of building models for planning maintenance activities, Proceedings of the International Conference on Computing in Civl and Building Engineering (ICCCBE) (Nottingham, Britain, 2010)

13. I. Motawa, A. Almarshad, A knowledge-based BIM system for building maintenance, Autom. Constr., 29, 173-182 (2013)

14. Z.-Z. Hu, X.-X. Chen, J.-P. Zhan, X.-W. Zhang, A BIM-based Research Framework for Monitoring and Management During Operation and Maintenance Period (Moskow, 2012)

15. M. T. Turkaslan-Bulbul, Ö. Akin, Computational support for building evaluation: embedded comissioning model, Autom. Constr., 15, 438-447 (2006)

16. S. Azhar, W. Carlton, D. Olsen, I. Ahmad, Building informationmodeling for sustainable design and LEED rating analysis, Autom. Constr., 20, 217-224 (2011)

17. U. Isikdag, S. Zlatanova, J. Underwood, A BIM-orientedmodel for supporting indoor navigation requirements, Comput. Environ. Urban. Syst., 41, 112-123 (2013)

18. B. Succar, Building information modelling framework: a research and delivery foundation for industry stakeholders, Autom. Constr., 18, 357-375 (2009) 
19. N. Gu, K. London, Understanding and facilitating BIMadoption in the AEC industry, Autom. Constr., 19, 988-999 (2010)

20. F. Cheung, J. Rihan, J. Tah, D. Duce, E. Kurul, Early stage multi-level cost estimation for schematic BIM models, Autom. Constr., 27, 67-77 (2012)

21. Z. Shen, R. Issa, Quantitative evaluation of the BIM-assisted construction detailed cost estimates, J. Inf. Technol. Constr. (ITcon), 15, 234-257 (2010)

22. T. Hartmann, H. VanMeerveld, N. Vossebeld, A. Adriaanse, Aligning building information model tools and construction management methods, Autom. Constr., 22, 605-613 (2012)

23. P. Yee, M. Fischer, J. Haymaker, Automated identification of occupant interactions in renovations of occupied buildings, ITcon, 18, 182-213 (2013)

24. D. Donath, T. Thurow, Integrated architectural surveying and planning: methods and tools for recording and adjusting building survey data, Autom. Constr., 16, 19-27 (2007)

25. V. Bazjanac, IFC BIM-Based Methodology for Semi-Automated Building Energy Performance Simulation (Lawrence Berkeley National Laboratory, Berkeley, 2008)

26. J. Zhang, Z.-Z. Hu, BIM- and 4D-based integrated solution of analysis and management for conflicts and structural safety problems during construction: 1. Principles and methodologies, Autom. Constr., 20, 155-166 (2011)

27. R. Sacks, R. Barak, Impact of three-dimensional parametric modeling of buildings on productivity in structural engineering practice, Autom. Constr., 17, 439-449 (2008)

28. S.-I. Lee, J.-S. Bae, Y.S. Cho, Efficiency analysis of set-based design with structural building information modeling (S-BIM) on high-rise building structures, Autom. Constr., 23, 20-32 (2012)

29. M. Murphy, E. McGovern, S. Pavia, Historic building information modelling (HBIM), Struct. Surv., 27, 311-327 (2009)

30. K. Yeh, M. Tsai, S. Kang, On-site building information retrieval by using projectionbased augmented reality, J. Comput. Civ. Eng., 26, 342-355 (2012)

31. ISO Standard, ISO 22263:2008-01: Organization of Information About Construction Works - Framework for Management of Project Information, International Standard, (2008)

32. R. Volk, J. Stengel, and F. Schultmann, "Building Information Modeling (BIM) for existing buildings - Literature review and future needs," Automation in Construction, 38, 109-127 (2014)

33. J. Armesto, I. Lubowiecka, C. Ordóñez, F. Rial, FEM modeling of structures based on close range digital photogrammetry, Autom. Constr., 18, 559-569 (2009)

34. F. Remondino, S. El-Hakim, Image-based 3D modelling: a review, Photogramm. Rec., 21, 269-291 (2006)

35. J. Markley, J. Stutzman, E. Harris, Hybridization of photogrammetry and laser scanning technology for as-built 3D CAD models, Conference Publications, 1-10 (2008)

36. C. P. Teizer, Leveraging passive RFID technology for construction resource, field mobility and status monitoring in a high-rise renovation project, Autom. Constr., 24, 115 (2012)

37. A. Motamedi, A. Hammad, Lifecycle management of facilities components using radio frequency identification and building information model, J. Inf. Technol. Constr. (ITcon), 14, 238-262 (2009) 
38. B. Domínguez, Á. García, F. Feito, Semiautomatic detection of floor topology from CAD architectural drawings, Comput. Aided Des., 44, 367-378 (2010)

39. N. Li, B. Becerik-Gerber, Life-cycle approach for implementing RFID technology in construction: learning from academic and industry use cases, J. Constr. Eng. Manag., 137, 1089-1098 (2011)

40. E. Valero, A. Adan, C. Cerrada, Automatic construction of 3D basic-semantic models of inhabited interiors using laser scanners and RFID sensors, Sensors, 12, 5705-5724 (2012)

41. S. El-Omari, O. Moselhi, Integrating 3D laser scanning and photogrammetry for progress measurement of construction work, Autom. Constr., 18, 1-9 (2008)

42. H. Hajian, B. Becerik-Gerber, Scan to BIM: factors affecting operational and computational errors and productivity loss, Proceedings of the 27th International Symposium on Automation and Robotics in Construction (ISARC) (2010)

43. L. Klein, N. Li, B. Becerik-Gerber, Image-based verification of as-built documentation of operational buildings, Autom. Constr., 21, 161-171 (2012)

44. A. Bhatla, S. Choe, O. Fierro, F. Leite, Evaluation of accuracy of as-built 3D modelling from photos taken by handheld digital cameras, Autom. Constr., 28, 116-127 (2012)

45. L. Barazetti, M. Scaioni, F. Remondino, Orientation and 3D modeling from markerless terrestrial images: combining accuracywith automation, Photogramm. Rec., 25, 356-381 (2010)

46. D. Huber, B. Akinci, A. Adan, E. Anil, B. Okorn, X. Xiong, Methods for automatically modeling and representing as-built building information models, Proceedings of the NSF CMMI Research Innovation Conference (2011)

47. A. Adan, D. Huber, Reconstruction of wall surfaces under occlusion and clutter in $3 D$ indoor environments, Proceedings of $3 D$ Imaging,Modeling, Processing, Visualization and Transmission (3DIMPVT) (Hangzhou, China, 2010)

48. X. Xiong, D. Huber, Using context to create semantic $3 D$ models of indoor environments, Proceedings of the British Machine Vision Conference (BMVC) (2010)

49. C. Clemen, L. Gründig, 3D building information efficiently acquired and managed, Proceedings of the FIG Commissions 5, 6 and SSGA Workshop, Lake Baikal, Listvyanka, Russian Federation, 12-19 (2009)

50. J. Dickinson, A. Pardasani, S. Ahamed, S. Kruithof, A survey of automation technology for realising as-built models of services, Improving construction and use through integrated design, solutions, 365-381 (2009)

51. Y. Arayici, Towards building information modelling for existing structures, Struct. Surv., 26, 210-222 (2008)

52. X. Xiong, A. Adan, B. Akinci, D. Huber, Automatic creation of semantically rich 3D building models from laser scanner data, Autom. Constr., 31, 325-337 (2013)

53. A. Adan, X. Xiong, B. Akinci, D. Huber, Automatic creation of semantically rich 3D building models from laser scanner data, Proceedings of the International Symposium on Automation and Robotics in Construction (ISARC) (2011)

54. J. Frahm, M. Pollefeys, S. Lazebnik, D. Gallup, B. Clipp, R. Raguram, C.Wu, C. Zach, T. Johnson, Fast robust large-scale mapping from video and internet photo collections, ISPRS J. Photogramm. Remote Sens., 65, 538-549 (2010)

55. B. Becerik-Gerber, F. Jazizadeh, G. Kavulya, G. Calis, Assessment of target types and layouts in 3D laser scanning for registration accuracy, Autom. Constr., 20, 649-658 (2011) 
56. F. Dai, M. Lu, V. Kamat, Analytical approach to augmenting site photos with 3D graphics of underground infrastructure in construction engineering applications, J. Comput. Civ. Eng., 66-74 (2011)

57. H. Fathi, I. Brilakis, Automated sparse 3D point cloud generation of infrastructure using its distinctive visual features, Adv. Eng. Inform., 25, 760-770 (2011)

58. Y. Furukawa, B. Curless, S. Seitz, R. Szeliski, Reconstructing building interiors from images, Proceedings of the International Conference on Computer Vision (ICCV), 8087 (2009)

59. C. Ordóñez, J. Martínez, P. Arias, J. Armesto, Measuring building facades with a lowcost close-range photogrammetry system, Autom. Constr., 19, 742-749 (2010)

60. A. Styliadis, L. Sechidis, Photography-based facade recovery \& 3Dmodelling: a CAD application in cultural heritage, J. Cult. Herit., 12, 243-252 (2011)

61. W. Yang, M. Chen, Y. Yen, An application of digital point cloud to historic architecture in digital archives, Adv. Eng. Softw., 42, 690-699 (2011)

62. S.-A. Kim, S. Chin, A.-W. Yoon, T.-H. Shin, Y.-S. Kim, C. Choi, Automated building information modeling system for building interior to improve productivity of BIM-based quantity take-off, 2009 Proceedings of the 26th ISARC, 492-496 (Austin, USA, 2009)

63. V. Singh, N. Gu, X. Wang, A theoretical framework of a BIM-based multidisciplinary collaboration platform, Autom. Constr., 20, 134-144 (2011)

64. M. Golparvar-Fard, J. Bohn, J. Teizer, S. Savarese, F. Pena-Mora, Evaluation of imagebased modeling and laser scanning accuracy for emerging automated performance monitoring techniques, Autom. Constr., 20, 1143-1155 (2011)

65. F. Leite, A. Akcamete, B. Akinci, G. Atasoy, S. Kiziltas, Analysis ofmodeling effort and impact of different levels of detail in building information models, Autom. Constr., 20, 601-609 (2011)

66. A. Johnson, R. Hoffman, J. Osborn, M. Hebert, A system for semi-automatic modeling of complex environments, Proceedings of the International Conference on Recent Advances in 3D digital Imaging and Modeling (Ottawa, Canada, 1997) 